\title{
Diagnostic Value of Ultrasound in Detection and Diagnosis of Plantar Fasciitis in Diabetic Foot Patients in Comparison with Magnetic Resonance Imaging
}

\author{
Ahmed Abdel Mohsen ${ }^{\text {a }}$, El-Sayed A. Abd El-Mabood ${ }^{\text {b }}$, Ahmed El-sayed ${ }^{\text {a }}$ \\ a Department of Radiology, \\ Faculty of Medicine Benha \\ University, Egypt. \\ b Department of General and \\ Vascular surgery, Faculty of \\ Medicine Benha University, \\ Egypt. \\ Correspondence to: Ahmed \\ Abdel Mohsen, Department of \\ Radiology, Faculty of Medicine \\ Benha University, Egypt. \\ Email: \\ ahmed.mohsen011@gmail.com \\ Received: 18 August 2021 \\ Accepted: 12 February 2022

\begin{abstract}
Background: Ultrasound has proved its ability to detect changed associated with plantar fasciitis (PF). However, magnetic resonance imaging (MRI) is still the gold standard technique for the diagnosis of such condition. Aim of the work: This study was conducted to evaluate the diagnostic capability of ultrasonography for the detection of plantar fasciitis in comparison with MRI in diabetic foot patients. Subjects and methods: This prospective case control study included 40 subjects; 30 cases diagnosed with PF in addition to 10 controls. All subjects were subjected to history taking, clinical examination, plantar US and MRI examination for assessment of PF signs. Results: Basic demographics were comparable between cases and controls. By both US and MRI, plantar fascial thickness showed a significant increase, in both longitudinal and transverse planes, in cases compared to controls. US had sensitivity and specificity of 92.6 and $100 \%$ respectively, with a diagnostic accuracy of $93.3 \%$
\end{abstract} \\ for the detection of focal thickening and fascial abnormal signaling. US had sensitivity and \\ specificity of 94.4 and $100 \%$ in detecting soft tissue edema, while it had poor sensitivity for \\ calcaneal spur, and no sensitivity for bone marrow edema. Conclusion: US could be considered \\ as good alternative tool compared to MRI in the diagnosis of PF, as it was able to detect most \\ signs of such pathology. However, it is recommended to be performed by an experienced \\ radiologist.
}

Key words: Plantar fasciitis; Ultrasound; MRI; Diabetic foot. 


\section{Introduction}

Plantar fasciitis (PF) is the most common etiology of heel pain, as it affects about $10 \%$ of the whole world population, and over 2 million American citizens every year [1]. This pathology is characterized by pain at the plantar surface of the foot that is often severe in the morning, and decreases on ordinary walking but increases with excessive activity [2]. Another pathognomonic character of that disease is tenderness at the medial calcaneal tubercle at the site of insertion of plantar fascia. Nevertheless, this sign could not be detected in all cases [3].

The etiology of this pathology is multifactorial. However, most physicians attributed it to the occurrence of micro tears in the connective tissue in the plantar region. These tears are the natural consequence of repetitive overload over connective tissue in the plantar region. Accumulation of microtears leads to structural damage and inflammation of this tissues resulting in pain and discomfort [4].

Patients with diabetes are at higher risk to get this disease. The diabetic patient often has other risks and comorbidities that could trigger that disease like obesity and sedentary life style. Additionally, hyperglycemia and glycation end products themselves increase the plantar fascial thickness, and increase the risk of PF [5].

The diagnosis of PF depends mainly on the clinical basis, and the application of diagnostic imaging in such cases is not a routine procedure for some practitioners [6]. However, some patients may present with atypical features, not respond to conservative or initial treatment plans. Therefore, the diagnosis must be confirmed by radiological studies [3].

Currently, magnetic resonance imaging (MRI) is the gold standard technique for the diagnosis of PF, as it is a sensitive tool for assessment of morphological changes and disease process in the plantar fascia $[7,8]$. Nevertheless, MRI has some disadvantages, it has high cost, not available at all centers and cannot be performed in patients with metallic prosthesis [9].

Foot ultrasonography (US) has proved its efficacy in detecting changes associated with PF disease including thickening of the plantar fascia, surrounding soft tissue edema, blurring of the boundaries between fascia and surrounding tissues, and 
hypoechogenicity at the insertion upon the calcaneus [10, 11]. Ultrasound has some advantages, it is fast, available and could be performed at the bedside [9]. However, it is highly operator-dependent requiring experience and long learning curve [12].

\section{Aim of the work}

This study was conducted to evaluate the diagnostic capability of ultrasonography for the detection of plantar fasciitis in comparison with MRI in diabetic foot patients.

\section{Subjects and methods}

This is a prospective case control study that was conducted at Surgery and orthopedic outpatient clinics in both Benha University and Hurghada General Hospitals over the period of one year, starting from January 2020 till January 2021.

We included a total of 40 subjects who were divided into two groups; Cases group included 30 diabetic cases clinically diagnosed with plantar fasciitis and confirmed by MRI, and Control group which included the remaining 10 age and gender matched healthy adult controls.

We included cases aged between 20 and 70 years, having type 2 diabetes with or without neuropathy, who presented with chronic heel pain suggestive of $\mathrm{PF}$, and confirmed by an MRI study. Contrarily, patients with trauma at the affected side, previous heel surgery, non-diabetics, or having a contraindication for MRI examination were excluded.

The study was approved by the local ethical committee and Institutional Review Board (IRB) of the faculty of medicine, Benha University. Additionally, an informed written consent was obtained from all of the included participants after complete explanation of the details, benefits and complications of each intervention.

All cases were subjected to detailed history taking, clinical examination and routine laboratory investigations. In addition, MRI and US were ordered for all participants. US and MRI images were evaluated by two different radiologists in a blinded fashion.

As regard the MRI examination, it was performed using a 1.5T Philips Gyroscan Achieva (Best, The Netherlands) closed configuration whole body scanner using an extremity coil. Patients were examined in the supine position, with strict instructions not to move their foot during examination. The surface col of the extremity was positioned over the foot, and the following protocols were used: 
- Sagittal T1 weighted images (TR 500-650 msec, TE $20 \mathrm{msec}$, slice thickness $2.5 \mathrm{~mm}$, gap $0.3 \mathrm{~mm}, \mathrm{FOV}=170 \mathrm{~mm}$ and $\mathrm{NSA}=2$ ).

- Sagittal T2 fat saturation images: (TR $4900 \mathrm{msec}$, TE $100 \mathrm{msec}$, slice thickness 3 $\mathrm{mm}$, gap $0.3 \mathrm{~mm}, \mathrm{FOV}=170 \mathrm{~mm}$ and $\mathrm{NSA}=1)$.

- Sagittal stir images (TR 4000- $5000 \mathrm{msec}$, TE $100 \mathrm{msec}$, TI $130 \mathrm{msec}$, slice thickness $3 \mathrm{~mm}$, gap $0.3 \mathrm{~mm}, \mathrm{FOV}=170 \mathrm{~mm}$ and NSA $=1)$.

- Coronal stir images (TR 4000- $5000 \mathrm{msec}$, TE $100 \mathrm{msec}$, TI $130 \mathrm{msec}$, slice thickness $3 \mathrm{~mm}$, gap $0.3 \mathrm{~mm}, \mathrm{FOV}=170 \mathrm{~mm}$ and NSA =1) (figure $1 \& 2$ ).
US assessment was performed using a 7-12 $\mathrm{MHz}$ linear transducer of the "Get logic p9 scanner" US device. Examination was performed when the patient was supine, with his feet on the table keeping ankle dorsiflexion of $90^{\circ}$. In the sagittal plane, the plantar fascial thickness was measured at its origin in both longitudinal and transverse sections. PF was diagnosed when the examiner detected plantar thickness more than $4 \mathrm{~mm}$ along with reduced echogenicity (figure 3\&4). Additional findings including edema or calcaneal spurs were reported and recorded.

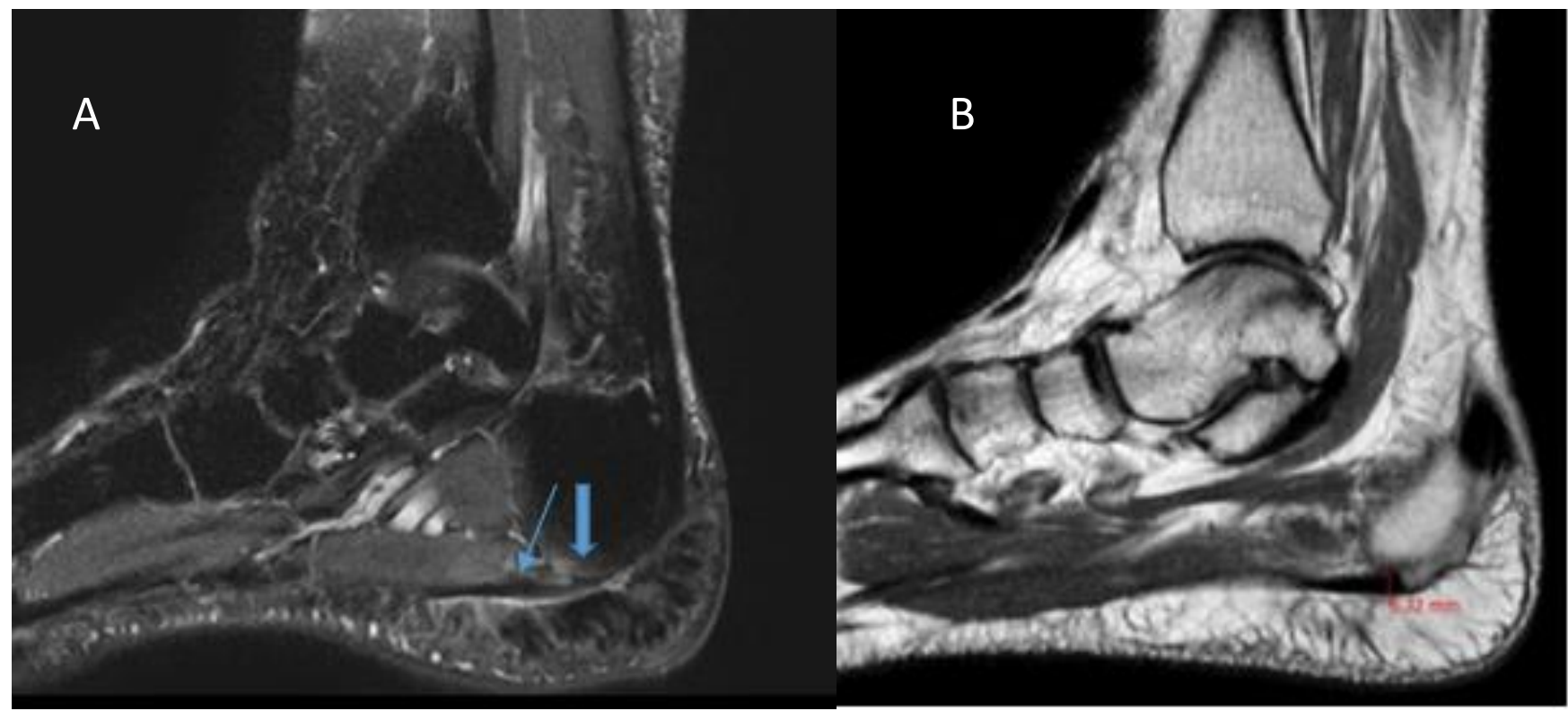

Figure (1):A- Sagittal (PDW - SPAIR) MR images showing focal thickening of the plantar fascia at its calcaneal origin with abnormal high signal intensity, this is associated with signal intensity changes in the peri-fascial soft tissues reflecting soft tissue edema (thin arrows). Hyper-intense signal of the underlying calcaneal attachment indicates calcaneal bone marrow edema (thick arrows). B- Sagittal T1-weighted MR images showing focal thickening of the plantar fascia at its calcaneal origin reaching $6.3 \mathrm{~mm}$ in maximum thickness. 


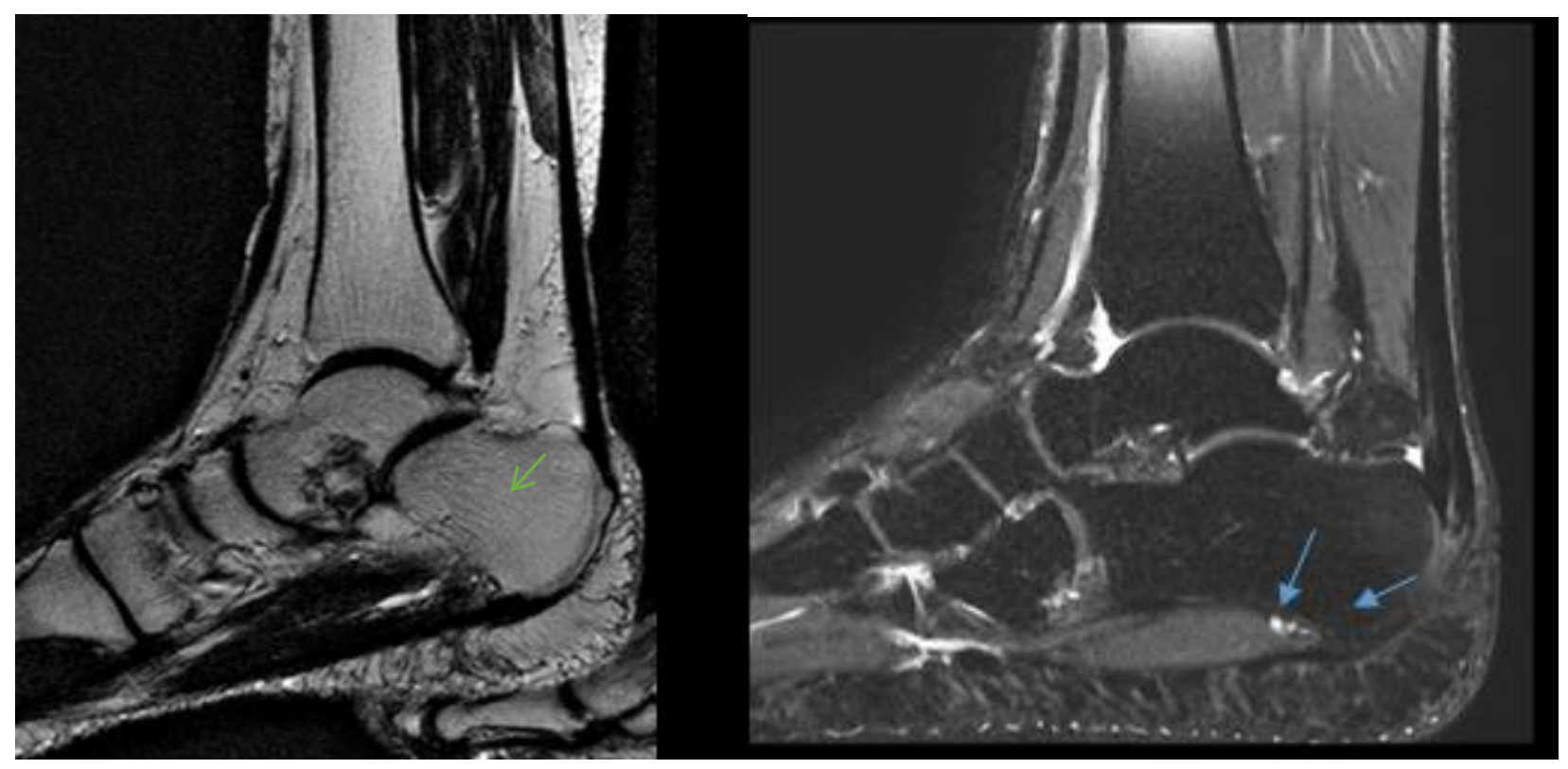

Figure (2): A- T1-weighted sagittal MR image of the plantar fascia showing focal thickening of the plantar fascia. Associated calcaneal spur was also noted (arrow).B- Sagittal PDW-SPAIR MR images showing the increased intrasubstance signal intensity of the thickened plantar fascia with surrounding hyper-intense peri-fascial soft tissue edema (thin arrows). The abnormal high marrow signal intensity at the calcaneal insertion reflecting underlying bone marrow edema was also noted.
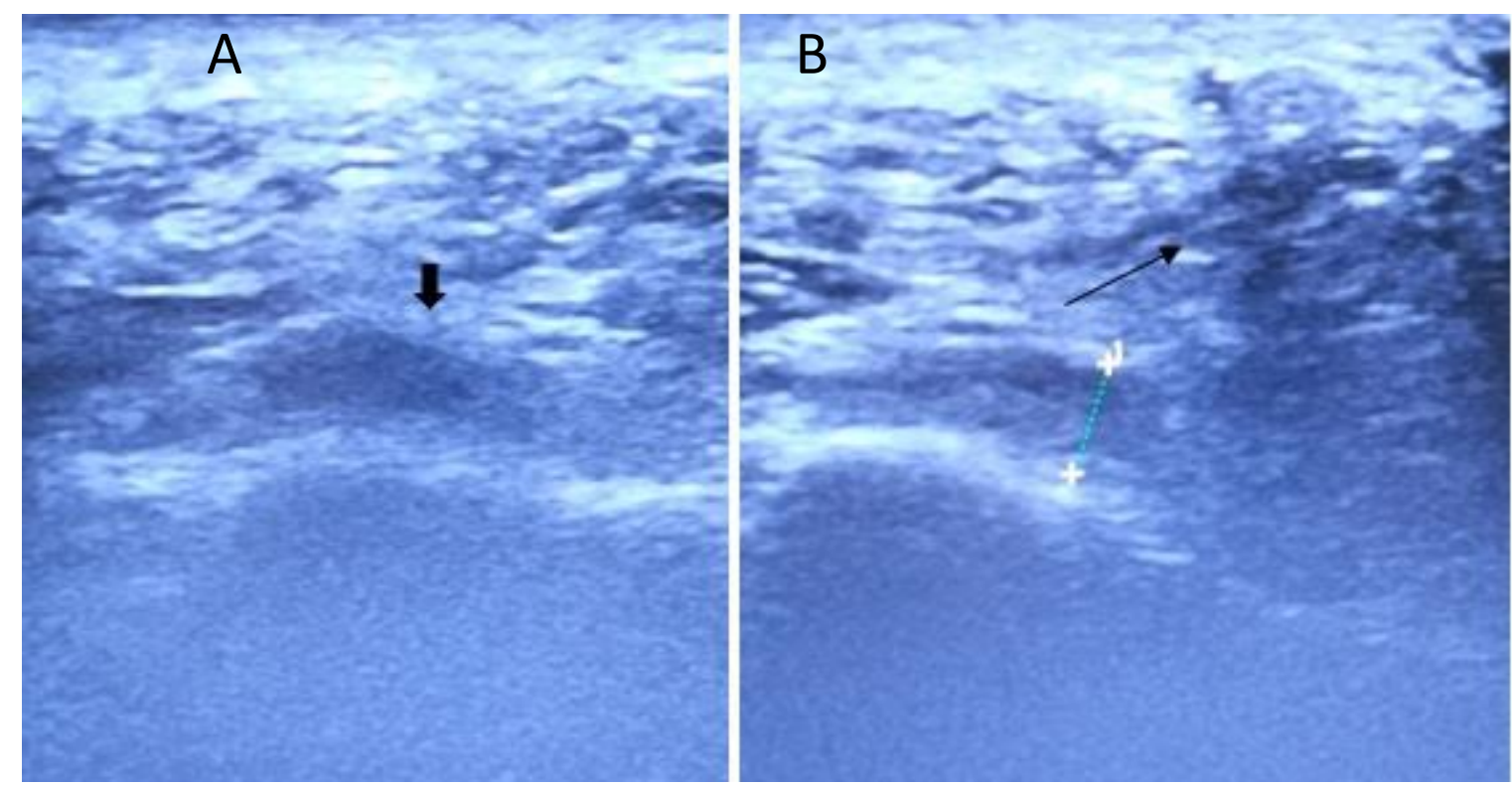

Figure (3): A-Sagittal ultrasonography of the heel revealed loss of edge sharpness of the fascia (thick arrows). BSagittal ultrasonography revealed prominently thickened hypo-echoic plantar fascia at its calcaneal origin measuring (7 mm) (cursors), Associated subcutaneous edema (thin arrows). 


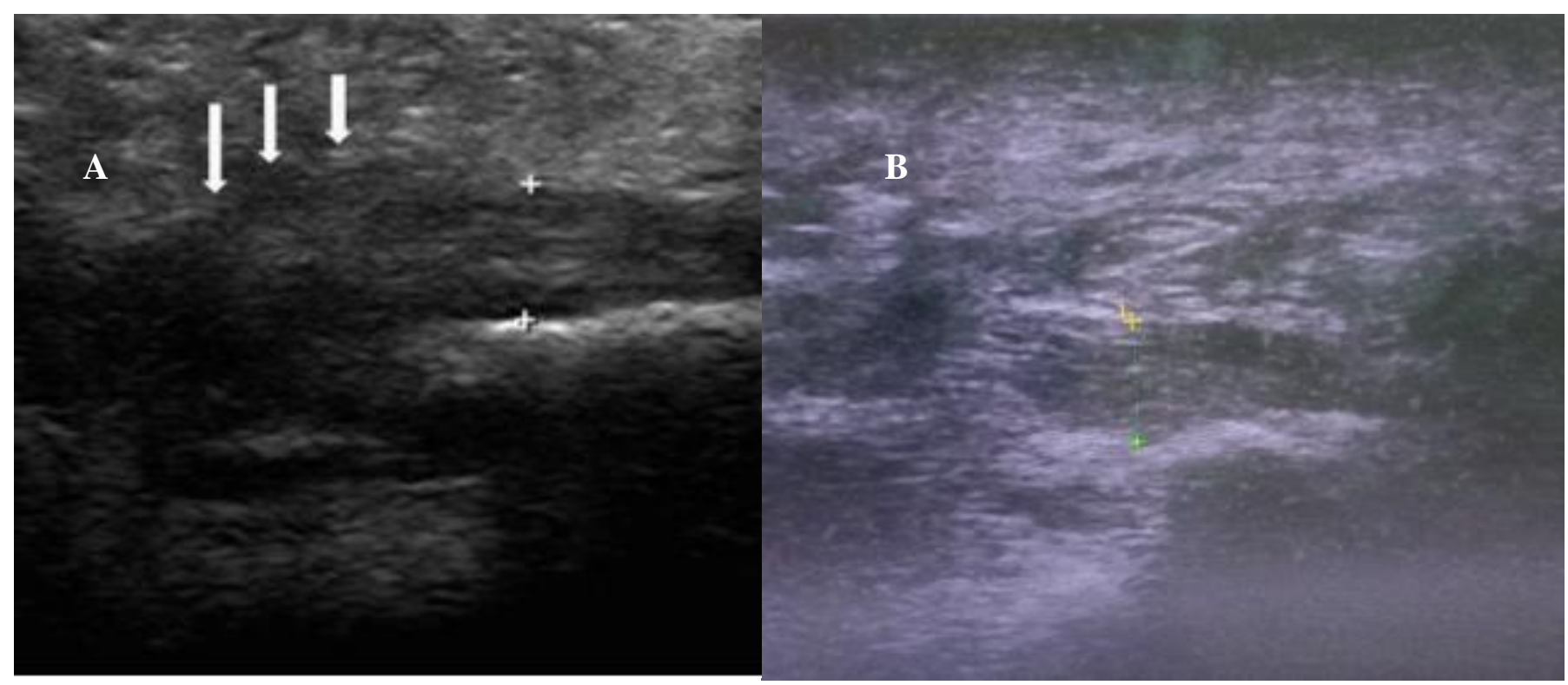

Figure (4): A-Sagittal ultrasonography of the heel revealed prominently thickened hypo-echoic plantar fascia at its calcaneal origin measuring $(6 \mathrm{~mm})$ (cursors), with loss of edge sharpness of the fascia associated subcutaneous edema (arrows).B- Sagittal ultrasonography of the heel revealed prominently thickened hypo-echoic plantar fascia at its calcaneal origin measuring $(5.7 \mathrm{~mm})$ (cursors).

\section{$\underline{\text { Statistical analysis }}$}

Recorded data were analyzed using the statistical package for social sciences, version 20.0 (SPSS Inc., Chicago, Illinois, USA). Quantitative data were expressed as mean \pm standard deviation (SD). Qualitative data were expressed as frequency and percentage. Chi-square (x2) test of significance was used in order to compare proportions between qualitative parameters. Diagnostic performance of US was assessed via sensitivity, specificity, positive predictive and negative predictive values. A $\mathrm{p}$ value less than 0.05 was considered significant.

\section{Results}

The mean age of the included subjects was 50.84 and 49.24 years in cases and control group respectively. Females represented 63.3 and $60 \%$ of the included participants in the same groups respectively, while the remaining portion was occupied by males. The mean values of BMI were 29.38 and $29.93 \mathrm{~kg} / \mathrm{m} 2$ in the same groups respectively. In general, no significant difference was noted between cases and controls regarding either of the previously mentioned variables. Table (1) illustrates these data. 
Benha medical journal, vol. 39, issue 1, 2022

Table (1): Demographic data in the cases and control groups.

\begin{tabular}{|c|c|c|c|}
\hline Items & $\begin{array}{l}\text { Cases group } \\
\qquad \begin{array}{c}\mathbf{n}=\mathbf{3 0} \\
\end{array}\end{array}$ & $\begin{array}{l}\text { Control group } \\
\qquad \begin{array}{r}n=10 \\
\end{array}\end{array}$ & $\begin{array}{c}\text { Test of } \\
\text { significance }\end{array}$ \\
\hline Age (years) & $50.84 \pm 6.25$ & $49.24 \pm 7.10$ & $\begin{array}{l}t=0.525 \\
P=0.602\end{array}$ \\
\hline \multicolumn{4}{|l|}{ Sex } \\
\hline Male & $11(36.7 \%)$ & $4(40 \%)$ & $\mathrm{FET}=1.381$ \\
\hline Female & $19(63.3 \%)$ & $6(60 \%)$ & $\mathrm{P}=0.123$ \\
\hline BMI $\left(\mathrm{Kg} / \mathrm{m}^{2}\right)$ & $29.38 \pm 3.24$ & $29.93 \pm 4.28$ & $\begin{array}{l}t=-0.510 \\
P=0.612\end{array}$ \\
\hline
\end{tabular}

Regarding the clinical presentation of the included cases, sharp heel pain in the morning was reported by 14 cases (46.7\%), while localized swelling was present in 7 cases $(23.3 \%)$. In addition, dull aching heel pain in the evening was present in 6 cases (20\%). Each of foot stiffness and limping gait was reported in three cases for each presentation (10\%). These data are illustrated at table (2).

Table (2): Clinical presentation in the cases included in the study.

\begin{tabular}{lc}
\hline \multicolumn{1}{c}{ Items } & Cases group (n= 30) \\
\hline Sharp heel pain in the morning & $14(46.7 \%)$ \\
Foot stiffness & $3(10 \%)$ \\
Localized swelling & $7(23.3 \%)$ \\
Limping gait & $3(10 \%)$ \\
Dull aching heel pain by the end of the day & $6(20 \%)$ \\
\hline
\end{tabular}

When measuring the thickness of plantar fascia at the origin by ultrasound, longitudinal thickness had mean values of 5.87 and $2.75 \mathrm{~mm}$, while the transverse thickness had mean values of 5.88 and 2.77 $\mathrm{mm}$ in cases and controls respectively. It was evident that both longitudinal and transverse thickness showed a significant increase in cases compared to controls $(\mathrm{p}<$ 0.001). 
When evaluating the same parameters by MRI, plantar fascial thickness was significantly increased in cases compared to controls ( $\mathrm{p}<0.001$ ), in both longitudinal and transverse planes. The former had mean values of 5.89 and $2.76 \mathrm{~mm}$, whereas the latter had mean values of 5.89 and $2.77 \mathrm{~mm}$ in cases and controls respectively. The previous data are shown at table (3).

Table (3): Ultrasound measurements of the average thickness of the plantar fascia ( $\mathrm{mm})$ in the two studied groups.

\begin{tabular}{llccc}
\hline & Items & Cases group & Control group & Test of significance \\
& & $\mathbf{n}=\mathbf{3 0}$ & $\mathbf{n}=\mathbf{1 0}$ & \\
\hline \multirow{2}{*}{ US } & Origin (LS) & $5.87 \pm 1.31$ & $2.75 \pm 0.36$ & $\mathrm{t}=6.148$ \\
& Origin (TS) & $5.88 \pm 1.33$ & $2.77 \pm 0.36$ & $\mathrm{t}=6.156$ \\
& & & $\mathrm{P}<0.001^{*}$ \\
& Origin (LS) & $5.89 \pm 1.29$ & $2.76 \pm 0.38$ & $\mathrm{t}=6.284$ \\
MRI & Origin (TS) & $5.89 \pm 1.30$ & $2.77 \pm 0.38$ & $\mathrm{t}=6.224$ \\
& & & $\mathrm{P}<0.001^{*}$ \\
\hline
\end{tabular}

When it comes to MRI findings in the same cases, focal thickening together with intrafascial abnormal signals were detected in 27 cases $(90 \%)$. Besides, calcaneal spur was noted in 25 cases $(83.3 \%)$ whereas soft tissue edema was noted in 18 cases $(60 \%)$. Bone marrow edema was detected in 10 cases $(33.33 \%)$.
Regarding US findings, both focal thickening and intra-fascial abnormal signals were detected in 25 cases $(83.3 \%)$, while soft tissue edema was encountered in 17 cases (56.7\%). In addition, calcaneal spur was detected in 7 cases $(23.3 \%)$. US examination was unable to detect bone marrow edema in all of the included cases. Table (4) illustrates these data.

Table (4): US and MRI results of the included cases.

\begin{tabular}{lcc}
\hline \multicolumn{1}{c}{ Items } & MRI & US \\
\hline Focal thickening & $27(90 \%)$ & $25(83.3 \%)$ \\
Intra-fascial abnormal signal & $27(90 \%)$ & $25(83.3 \%)$ \\
Soft tissue edema & $18(60 \%)$ & $17(56.7 \%)$ \\
Underlying calcaneal BM edema & $10(33.3 \%)$ & $0(0 \%)$ \\
Calcaneal spur & $25(83.3 \%)$ & $7(23.3 \%)$ \\
\hline
\end{tabular}


On comparing US with MRI regarding the detection of focal thickening, it had sensitivity and specificity of 92.6 and $100 \%$ respectively, with a diagnostic accuracy of $93.3 \%$.

When evaluating the ability of US to detect abnormal intra-fascial signal compared to MRI, it had a sensitivity of $92.6 \%$, while specificity was $100 \%$. The diagnostic accuracy of US was $93.3 \%$ in detecting that parameter.

US had sensitivity and specificity of 94.4 and $100 \%$ in detecting soft tissue edema, with a diagnostic accuracy of $96.7 \%$ compared to MRI. US had poor sensitivity for the detection of calcaneal spur (20\%) whereas its specificity was $60 \%$ compared to MRI. The diagnostic accuracy of US was $26.7 \%$ to detect that parameter.

US had no sensitivity for the detection of bone marrow edema (0\%) whereas its specificity was $100 \%$ compared to MRI. The diagnostic accuracy of US was $66.7 \%$ to detect that parameter. The previous data are summarized at table (5).

Table (5): Correlation between US findings and MRI regarding PF radiological signs.

\begin{tabular}{|c|c|c|c|c|c|c|c|c|}
\hline \multirow[t]{2}{*}{ Pathology } & \multirow[t]{2}{*}{ US result } & \multicolumn{2}{|c|}{ MRI results } & \multirow[t]{2}{*}{ Sensitivity } & \multirow[t]{2}{*}{ Specificity } & \multirow[t]{2}{*}{ PPV } & \multirow[t]{2}{*}{ VPV } & \multirow[t]{2}{*}{ Accuracy } \\
\hline & & Negative & Positive & & & & & \\
\hline \multirow{2}{*}{$\begin{array}{l}\text { Focal } \\
\text { thickening }\end{array}$} & Negative & 3 & 2 & \multirow{2}{*}{$92.6 \%$} & \multirow{2}{*}{$100 \%$} & \multirow[b]{2}{*}{$100 \%$} & \multirow[b]{2}{*}{$92.6 \%$} & \multirow{3}{*}{$93.3 \%$} \\
\hline & Positive & 0 & 25 & & & & & \\
\hline \multirow{2}{*}{$\begin{array}{l}\text { Fascial } \\
\text { abnormal } \\
\text { signal }\end{array}$} & Negative & 3 & 2 & \multirow[b]{2}{*}{$92.6 \%$} & \multirow[b]{2}{*}{$100 \%$} & \multirow[b]{2}{*}{$100 \%$} & \multirow[b]{2}{*}{$92.6 \%$} & \\
\hline & Positive & 0 & 25 & & & & & $93.3 \%$ \\
\hline \multirow{3}{*}{$\begin{array}{l}\text { Soft tissue } \\
\text { edema } \\
\text { Calcaneal } \\
\text { spur }\end{array}$} & Negative & 12 & 1 & \multirow[t]{2}{*}{$94.4 \%$} & \multirow[t]{2}{*}{$100 \%$} & \multirow[t]{2}{*}{$100 \%$} & \multirow[t]{2}{*}{$94.4 \%$} & \multirow[t]{2}{*}{$96.7 \%$} \\
\hline & $\begin{array}{l}\text { Positive } \\
\text { Negative }\end{array}$ & $\begin{array}{l}0 \\
3\end{array}$ & $\begin{array}{l}17 \\
20\end{array}$ & & & & & \\
\hline & Positive & 2 & 5 & $20 \%$ & $60 \%$ & $71.4 \%$ & $13.1 \%$ & $26.7 \%$ \\
\hline \multirow{2}{*}{$\begin{array}{l}\text { Bone } \\
\text { marrow } \\
\text { edema }\end{array}$} & Negative & 20 & 10 & \multirow[b]{2}{*}{$0 \%$} & \multirow[b]{2}{*}{$100 \%$} & \multirow[b]{2}{*}{ - } & \multirow[b]{2}{*}{$66.67 \%$} & \multirow[b]{2}{*}{$66.67 \%$} \\
\hline & Positive & 0 & 0 & & & & & \\
\hline
\end{tabular}

\section{Discussion}

The current study was conducted at Benha University Hospitals along with Hurghada General hospital aiming to evaluate the diagnostic capability of ultrasonography for the detection of plantar fasciitis in comparison with MRI in diabetic foot patient. We included a total of 30 cases diagnosed with diabetic plantar fasciitis (proved by MRI) in addition to age and gender matched healthy controls. The mean 
age of the included cases was 50.84 years compared to 49.24 years in controls, with no significant difference between the two groups regarding that parameter $(\mathrm{p}=0.602)$.

It was previously reported that the peak incidence occurs between ages 40 and 60 years in the general population [1], which comes in line with our findings. A previous study confirmed this findings, as they reported that cases and controls had mean ages of 48.6 and 48.4 years respectively, with no difference between the two groups [13].

In the current study, females represented 63.3 and $60 \%$ of the included participants in cases and controls respectively, with no significant difference between the two groups. Another study also reported that this pathology is more common in females who represented $85.71 \%$ of the included cases diagnosed with PF [14]. Other authors confirmed the previous findings [15].

Our study showed no significant difference between cases and controls regarding their BMI ( $p=0.123)$, which had mean values of 29.38 and $29.39 \mathrm{~kg} / \mathrm{m} 2$ in cases and controls respectively. Conversely, another study reported a significant increase in the BMI in PF cases compared to controls ( $\mathrm{p}<0.05$ ). BMI had mean values of 34.2 and 25.2 $\mathrm{kg} / \mathrm{m} 2$ in cases and controls respectively [14]. Other authors reported the previous findings [13]. However, in the absence of any prospective cohort studies in the general population, the causal role of being overweight or obese is unclear [2].

When it comes to plantar fascial thickness measurement in the current study, it showed a significant increase in cases compared to controls by both radiological modalities. By US, longitudinal thickness had mean values of 5.87 and $2.75 \mathrm{~mm}$, while the transverse thickness had mean values of 5.88 and 2.77 $\mathrm{mm}$ in cases and controls respectively. By MRI, longitudinal thickness had mean values of 5.89 and $2.76 \mathrm{~mm}$, whereas the transverse one had mean values of 5.89 and $2.77 \mathrm{~mm}$ in cases and controls respectively.

Plantar fascial thickening is an established ultrasonography sign for the diagnosis of $\mathrm{PF}$, and this has been confirmed in previous studies [16]. This is in accordance with a previous author who reported that the thickness of the plantar fascia in symptomatic feet was $(3.0-7.0 \mathrm{~mm} ; 4.9 \pm$ 1.3) and (2.5 - $6.9 \mathrm{~mm} ; 5.14 \pm 0.13)$ measured by ultrasound and MRI, respectively, and the plantar fascia by ultrasound of symptomatic feet was significantly thicker than in the control 
group $(1.1-2.4 \mathrm{~mm} ; 1.7 \pm 0.06) ; \mathrm{P}<0.05$ [17].

Moreover another authors reported that the thickness of the plantar fascia had mean values of 5.6 and $3.0 \mathrm{~mm}$ by MRI, while US values were 4.9 and $3.2 \mathrm{~mm}$ in cases and controls respectively. The authors reported a significant increase in plantar fascial thickness in patients with plantar fasciitis [14].

A previous study reported that ultrasonographic measurements of fascial thickness had mean values of $3.9 \mathrm{~mm}$ in cases versus $2.1 \mathrm{~mm}$ in controls [15]. Also another authors reported that PF had mean thickness of 3.7, 2.7, and $2.4 \mathrm{~mm}$ in cases, older controls, and healthy controls respectively, with a significant increase in that parameter in PF cases $(p<0.001)[18]$.

It appears that there is agreement between different studies regarding the increase in fascial thickness in PF cases by US. However, some differences could be anticipated in the measurements, and that could be attributed to difference in disease severity or operator experience.

In our study, US was able to detect abnormal fascial signal in 25 cases out of 27 detected by MRI. US had a sensitivity of $92.6 \%$, while specificity was $100 \%$. The diagnostic accuracy of US was $93.3 \%$ in detecting that parameter.

It should be mentioned that abnormal fascial signaling (hypoechogenicity) was a frequent finding in a previous study [19]; it was not a constant feature in another study report [20]. Of note, Hypoechoic fasciitis is analogous to that seen in tendonitis and could be related to an underlying reparative process of microtears, fiber degeneration, or edema [21]. A previous study reported that ultrasound examination $19(82.6 \%)$ of the symptomatic heels showed abnormal focal low echogenicity in the plantar fascia and 18 $(78.2 \%)$ of the same group showed abnormally high T2-weighted signal intensity within the plantar fascia on MRI examination. When MRI was considered as a reference, the statistical diagnostic accuracy of ultrasound was $69.5 \%$ [17].

On the other hand, another study [22] have shown that echotexture changes were not constantly observed, and perifascial changes also were seen in less than $5 \%$ of patients, and all of these changes were better observed on MRI [23].

In the current study, US was able to detect soft tissue edema in 17 out of the total 18 cases having edema by MRI. US had sensitivity and specificity of 94.4 and $100 \%$ 
in detecting soft tissue edema, with a diagnostic accuracy of $96.7 \%$ compared to MRI. A previous study reported that the diagnostic accuracy of US regarding surrounding soft tissue edema was $60.8 \%$. Edema around the plantar fascia and/or in the adjacent soft tissues of the symptomatic heels was detected by ultrasound in five cases and by MRI in 12 cases [17].

The detection rate of soft tissue edema in PF cases by US varies in the current literature. Another author reported that peri-fascial edema was detected by ultrasonography in $29.9 \%$ of the cases [14]. Conversely, perifacsial edema as reported by a previous study was detected by ultrasound in $5 \%$ of the cases [24], by another study in $10 \%$ of the cases [15] and by third one in $2.5 \%$ of the cases [25].

In our study, US were able to detect calcaneal spur in only 7 out of the 25 cases diagnosed with spur by MRI. US had poor sensitivity for the detection of calcaneal spur (20\%) whereas its specificity was $60 \%$ compared to MRI. Regarding calcaneal spurs in other studies, it was detected by ultrasound in two cases compared to 12 by MRI, making the statistical diagnostic accuracy of US 56.5\% in identifying such pathology [17]. This is in agreement with our findings. A previous study reported bony spurs by ultrasonography in $24 \%$ of the cases [24] while another study reported bony calcaneal spurs by ultrasonography in $51 \%$ of the cases [25].

In the current study, US was unable to detect bone marrow edema diagnosed by MRI in 10 cases. Therefore, it had $0 \%$ sensitivity and $100 \%$ specificity on evaluating such parameter. Limited bone marrow edema in the sub periosteal part of the medial calcaneal tuberosity may be observed in plantar fasciitis [14]. Other authors observed trabecular bone edema, an association of plantar bursitis, in seven cases using MRI; this could not be visualized using ultrasound [17].

All in all, our findings showed that US may act as a reliable diagnostic tool for $\mathrm{PF}$ despite being deficient in some parameters like bone marrow edema and calcaneal spurs. These drawbacks could be decreased by increasing training programs and using more recent US devices with high resolution imaging.

Our study has some limitations; first of all, it is a single center study that included a relatively small sample size. Additionally, PF cases should have been managed and followed up by US to evaluate US changes 
after treatment. These drawbacks should be well covered in the upcoming studies

\section{Conclusion}

Based on the previous findings, US could be considered as good alternative tool compared to MRI in the diagnosis of PF, as it was able to detect most signs of such pathology. However, it is recommended to be performed by an experienced radiologist. MRI should be reserved for doubtful cases.

\section{References}

[1] Nahin RL. Prevalence and pharmaceutical treatment of plantar fasciitis in United States adults. The Journal of Pain 2018;19(8):885-96.

[2] Buchbinder R. Plantar fasciitis. In: Isaac Z, Curtis MR, editors. UpToDate. Online: Wolters Kluwer; 2021.

[3] Al-Boloushi Z, López-Royo M, Arian M, GómezTrullén $\boldsymbol{E}$, Herrero $\boldsymbol{P}$. Minimally invasive nonsurgical management of plantar fasciitis: A systematic review. Journal of bodywork and movement therapies 2019;23(1):122-37.

[4] Menon NA, Jain J. Plantar fasciitis: A review. Indian Journal of Pain 2018;32(1):24.

[5] Gariani K, Waibel FW, Viehöfer AF, Uçkay I. Plantar fasciitis in diabetic foot patients: risk factors, pathophysiology, diagnosis, and management. Diabetes, metabolic syndrome and obesity: targets and therapy 2020;13:1271.
[6] Owens JM. Diagnosis and management of plantar fasciitis in primary care. The Journal for Nurse Practitioners 2017;13(5):354-9.

[7] Fazal MA, Tsekes D, Baloch I. Is there a role for MRI in plantar heel pain. Foot \& ankle specialist 2018;11(3):242-5.

[8] Recht MP, Donley BG. Magnetic resonance imaging of the foot and ankle. JAAOS-Journal of the American Academy of Orthopaedic Surgeons 2001;9(3):187-99.

[9] Draghi F, Gitto S, Bortolotto C, Draghi AG, Belometti GO. Imaging of plantar fascia disorders: findings on plain radiography, ultrasound and magnetic resonance imaging. Insights into imaging 2017;8(1):69-78.

[10] Groshar D, Alperson M, Toubi A, Gorenberg M, Liberson A, Bar-Meir E. Plantar fasciitis: detection with ultrasonography versus bone scintigraphy. The Foot 2000;10(3):164-8.

\section{[11] Radwan A, Wyland M, Applequist L, Bolowsky} E, Klingensmith H, Virag I. Ultrasonography, an effective tool in diagnosing plantar fasciitis: a systematic review of diagnostic trials. International journal of sports physical therapy 2016;11(5):663.

\section{[12] Kane D, Grassi W, Sturrock R, Balint P.} Musculoskeletal ultrasound-a state of the art review in rheumatology. Part 2: clinical indications for musculoskeletal ultrasound in rheumatology. Rheumatology 2004;43(7):829-38.

[13] Werner RA, Gell N, Hartigan A, Wiggerman N, Keyserling WM. Risk factors for plantar fasciitis among assembly plant workers. PM\&R 2010;2(2):110-6. 
[14] Sabir N, Demirlenk S, Yagci B, Karabulut N,

Cubukcu S. Clinical utility of sonography in diagnosing plantar fasciitis. Journal of ultrasound in medicine 2005;24(8):1041-8.

[15] Akfirat M, Sen C, Günes T. Ultrasonographic appearance of the plantar fasciitis. Clinical imaging 2003;27(5):353-7.

[16] Blankenbaker DG, De Smet AA. The role of ultrasound in the evaluation of sports injuries of the lower extremities. Clinics in sports medicine 2006;25(4):867-97.

[17] Abdel-wahab N, Fathi S, AL-EMADI S, Mahdi

$S$. High-resolution ultrasonographic diagnosis of plantar fasciitis: a correlation of ultrasound and magnetic resonance imaging. International Journal of Rheumatic Diseases 2008;11(3):279-86.

[18] Wu C-H, Chang K-V, Mio S, Chen W-S, Wang

T-G. Sonoelastography of the plantar fascia. Radiology 2011;259(2):502-7.

[19] Cardinal E, Chhem RK, Beauregard CG,

Aubin B, Pelletier M. Plantar fasciitis: sonographic evaluation. Radiology 1996;201(1):257-9.
[20] Gibbon WW. Plantar fasciitis: US imaging. Radiology 1992;182(1):285-.

[21] Theodorou DJ, Theodorou SJ, Kakitsubata Y, Lektrakul N, Gold GE, Roger B, et al. Plantar fasciitis and fascial rupture: MR imaging findings in 26 patients supplemented with anatomic data in cadavers. Radiographics 2000;20(suppl_1):S181S97.

[22] Wall JR, Harkness MA, Crawford A. Ultrasound diagnosis of plantar fasciitis. Foot \& ankle 1993;14(8):465-70.

[23] DeMaio M, Paine R, Mangine RE, Drez D. Plantar fasciitis. Orthopedics 1993;16(10):1153-63.

[24] Gibbon W, Long G. Plantar fasciitis: US evaluation. Radiology 1997;203(1):290a-.

[25] Ozdemir H, Yilmaz E, Murat A, Karakurt L, Poyraz AK, Ogur E. Sonographic evaluation of plantar fasciitis and relation to body mass index. European journal of radiology 2005;54(3):443-7.

To cite this article: Ahmed Abdel Mohsen, El-Sayed A. Abd El-Mabood, Ahmed El-sayed. Diagnostic Value of Ultrasound in Detection and Diagnosis of Plantar Fasciitis in Diabetic Foot Patients in Comparison with Magnetic Resonance Imaging. BMFJ 2022;39(1):136-149. DOI: 10.21608/bmfj.2021.91439.1459 